\title{
Aetiology of genital ulceration in the Gambia
}

\author{
D C W MABEY, R A WALL, C S S BELLO \\ From the Medical Research Council Laboratories, Fajara, the Gambia
}

SUMMARY The aetiology of genital ulceration was studied in 104 unselected patients (94 men, 10 women) attending a sexually transmitted disease (STD) clinic in the Gambia. Chancroid was diagnosed in $54(52 \%)$, syphilis in $23(22 \%)$, lymphogranuloma venereum (LGV) in seven (7\%), and herpes in six (6\%). In $28(27 \%)$ patients no diagnosis was reached. Ten $(10 \%)$ patients were found to have both chancroid and syphilis, three $(3 \%)$ had both LGV and syphilis, and one $(1 \%)$ had both herpes and syphilis. Trimethoprim $160 \mathrm{mg}$ and sulphamethoxazole $800 \mathrm{mg}$ twice daily for one week was found to be effective in the treatment of chancroid. This regimen with a single intramuscular injection of benzathine penicillin $2.4 \mathrm{MIU}$ is recommended for the treatment of genital ulcers in Gambian health centres without laboratory facilities.

The incidence of genital ulceration is extremely high in many parts of Africa, and in some areas is believed to be similar to that of urethritis. ${ }^{1-6}$ Whereas most genital ulcers in developed countries are due to herpes simplex virus, ${ }^{78}$ this has not been found to be the case in the African countries in which studies have been carried out. ${ }^{569}$

It has long been felt on clinical grounds that, even in areas of Africa where syphilis is highly prevalent, most genital ulcers are due to chancroid. ${ }^{1}{ }^{4}$ The clinical diagnosis of genital ulcers is unreliable, however, ${ }^{1011}$ and only in recent years have improved culture techniques enabled this impression to be confirmed microbiologically. Haemophilus ducreyi was isolated in Nairobi from $62 \%$ of 97 patients with genital utcers, ${ }^{5}$ and in Johannesburg from $61 \%$ of 102 patients. $^{6}$

To our knowledge, the aetiology of genital ulceration has not been systematically studied in west Africa, although the isolation of $H$ ducreyi has been reported from three patients in Nigeria. ${ }^{12}$ The aim of the present study was to investigate the aetiology of genital ulceration in patients attending a clinic for sexually transmitted diseases (STDs) in the Gambia.

Address for reprints: Dr D C W Mabey, Department of Clinical Tropical Medicine, London School of Tropical Medicine and Hygiene, Keppel Street, London WC1E 7HT

Accepted for publication 6 January 1987.

\section{Patients and methods}

\section{PATIENTS}

The Gambia is a small predominantly Muslim country on the west coast of Africa between latitudes 13 and $14^{\circ} \mathrm{N}$. At Fajara, on the coast, an STD clinic was established in the Medical Research Council hospital in 1980 . The present study describes the findings in 104 unselected patients ( 94 men, 10 women) attending this clinic with genital ulceration. All were investigated by dark field microscopy, culture for herpes simplex virus and $H$ ducreyi, and serological tests for infection with Treponema pallidum, herpes simplex virus, or Chlamydia trachomatis serotypes L1-3.

\section{LABORATORY METHODS}

\section{Dark field microscopy}

After the base of the ulcer had been cleaned with normal saline, a drop of exudate was placed on a slide and examined immediately under dark field illumination at a magnification of $\times 400$. T pallidum was identified by its characteristic morphology and mobility.

\section{Culture of herpes simplex virus}

Swabs taken from the base of the ulcer were immediately expressed into viral transport medium containing $10 \%$ fetal calf serum and stored at $-70^{\circ} \mathrm{C}$. They were subsequently inoculated on to Vero cells in minimum essential medium with $5 \%$ fetal calf serum, and the cells were examined daily for cytopathic effect for 
two weeks. Herpes simplex virus was identified by its characteristic cytopathic effect.

\section{Culture of $H$ ducreyi}

The ulcer was cleaned thoroughly with sterile normal saline, and swabs were taken from the base of the ulcer. These were inoculated directly on to each of two culture media. One contained $10 \%$ sheep blood in Columbia agar base (Oxoid Ltd) and the other 7\% chocolated horse blood in Columbia agar base. Each was enriched with $5 \%$ fetal calf serum and vitox (Oxoid Ltd) and made selective with vancomycin (3 mg/l).

Plates were incubated for up to 10 days at $33^{\circ} \mathrm{C}$ in a candle extinction jar containing a moistened paper towel. They were inspected daily and $H$ ducreyi was identified by colonial morphology, Gram stain, and standard biochemical techniques. ${ }^{13}$

\section{Cultures of $C$ trachomatis}

Swabs taken from the base of the ulcer were expressed immediately into sucrose phosphate (2SP) transport medium containing $10 \%$ fetal calf serum, and stored at $-70^{\circ} \mathrm{C}$. They were subsequently inoculated, with centrifugation, on to cycloheximide treated McCoy cells, which were stained with Giemsa and examined for inclusions after incubation for 48 hours. ${ }^{14}$

\section{Serological tests}

The Venereal Disease Research Laboratory (VDRL) test was performed according to standard techniques using undiluted serum and Wellcome reagent VD 02-03. The $T$ pallidum haemagglutination assay (TPHA) was performed according to standard techniques using serum at dilutions of $1: 80$ and $1: 160$ with reagent obtained from Fujizoki Pharmaceutical Company, Tokyo.

Sera were screened for IgG antibodies to $C$ trachomatis serotypes $\mathrm{L} 1-3$ at a dilution of 1:250. A microimmunofluorescence (MIF) test was used with egg grown chlamydial antigens kindly supplied by Dr M Tam. ${ }^{15}$

IgG antibodies to herpes simplex were measured by MIF in 28 patients from whom paired sera were available. Herpes simplex infected Vero cells were used as antigen, and sera were tested at doubling dilutions from $1: 8$ to $1: 256 .^{16}$

\section{TREA TMENT}

All patients were treated with co-trimoxazole two tablets daily for one week (each tablet containing $80 \mathrm{mg}$ trimethoprim and $400 \mathrm{mg}$ sulphamethoxazole). They were also advised to wash their ulcers four times daily in salt water. Those who were dark ground or VDRL positive were also treated with either a single intramuscular injection of benzathine penicillin $2 \cdot 4$
MIU or 10 daily intramuscular injections of procaine penicillin $600000 \mathrm{IU}$. They were asked to return for follow up one and four weeks after their first visit. Those who did not show a considerable improvement after one week were in most cases treated with the same regimen of co-trimoxazole for a further week.

\section{Results}

Of the 104 patients with genital ulceration seen, 10 were women (mean age $25 \cdot 6$, range 15 to 45 ) and 94 were men (mean age 28.9 , range 17 to 75 ). None of the women had had sexual contact other than with a single regular partner. Of the men $42(44 \%)$ appeared to have been infected by a prostitute or other casual sexual contact. All but two of the men were circumcised. Fifty two patients had received treatment before they were seen. In 10 patients this consisted only of topical application of antiseptic or antibiotic ointment, the other 42 had taken systemic antibiotics. In most cases treatment comprised less than 10 capsules of tetracycline or fewer than three injections of penicillin. Only six patients had received a course of treatment possibly effective against syphilis.

Table 1 shows the duration of symptoms when the patients were first seen. In $57(55 \%)$ patients more than one ulcer was present. In $42(40 \%)$ inguinal glands greater than $1 \mathrm{~cm}$ in diameter were noted, unilaterally in 29 and bilaterally in 13 . In 12 cases these were fluctuant or discharging.

$H$ ducreyi was isolated from 54 (52\%) patients; 34 were isolation negative and in 16 cases cultures were overgrown with contaminants. Thus, excluding patients whose cultures were contaminated, $H$ ducreyi was isolated from 54 of $88(61 \%)$ patients.

Positive VDRL and TPHA test results suggestive of active syphilis were found in $22(21 \%)$ patients; four of these were dark ground positive. A further patient, whose ulcer had been present for one week, was dark ground positive but serologically negative. Four patients had positive TPHA but negative VDRL results, which suggested a previous treponemal infection.

Seven patients had chlamydial antibody titres of 1:250 or greater, which suggested that they were

Table 1 Duration of genital ulceration reported at initial presentation of 104 patients

\begin{tabular}{ll}
\hline Duration & No of patients \\
\hline$<1$ week & 22 \\
1 week - & 28 \\
2 weeks - & 16 \\
3 weeks - & 12 \\
1 month - & 14 \\
2 months - & 4 \\
3 months + & 8 \\
\hline
\end{tabular}


suffering from lymphogranuloma venereum (LGV). Three of them also had serological evidence of syphilis.

Herpes simplex virus was isolated from four (4\%) patients. In a further two patients there was a fourfold increase in antibody titre to herpes simplex virus; one of these patients also had syphilis. Table 2 summarises the diagnoses reached.

At least one follow up visit was made by $74(71 \%)$ patients. Complete healing of the ulcers was noted at one week in 29 of these $(39 \%)$ and at subsequent follow up in a further $20(27 \%)$. Twenty one $(28 \%)$ patients were noted to be improving after one week but were lost to subsequent follow up. Four, two of whom had positive serological test results for syphilis, showed no improvement at one week and were lost to follow up.

\section{Discussion}

The incidence of genital ulceration in the Gambia is not known, but in our clinic we see comparable numbers of cases of genital ulceration and urethritis. Government health centres and hospitals in the Gambia treat 16000 men with urethral discharge a year (Jack A, personal communication). As there are thought to be fewer than 200000 adult men in the Gambia (1973 census), the incidence of urethritis is likely to be about $10 \%$ a year.

Syphilis is known to be prevalent in the Gambia, where endemic treponematoses are now rare. At an urban antenatal clinic a prevalence of $1 \%$ was found, ${ }^{17}$ and at a rural clinic a prevalence of $11 \%$ (Mabey D, unpublished observation), diagnosed by positive VDRL and TPHA results. Nevertheless, we have found that only $22 \%$ of genital ulcers seen in our clinic are due to syphilis. The low proportion of dark ground positive patients is presumably due to the high incidence of previous medication.

The results of the present study are remarkably similar to those from Nairobi ${ }^{5}$ and Johannesburg. ${ }^{6}$ Excluding patients whose cultures were contaminated, we isolated $H$ ducreyi from $61 \%$ of genital ulcers, compared with $62 \%$ in Nairobi and $61 \%$ in Johannesburg, and herpes simplex virus from $4 \%$

Table 2 Diagnosis of 104 patients

\begin{tabular}{lc}
\hline Diagnosis & No (\%) of patients \\
\hline Chancroid & $54(52)$ \\
Syphilis & $23(22)$ \\
Lymphogranuloma venereum & $7(7)$ \\
Herpes & $6(6)$ \\
No diagnosis & $28(27)$ \\
\hline
\end{tabular}

Ten $(10 \%)$ patients had chancroid and syphilis, three $(3 \%)$ had lymphogranuloma venereum and syphilis, and one had herpes and syphilis. compared with $4 \%$ in Nairobi and $9 \%$ in Johannesburg. The corresponding figures for syphilis are $22 \%$ (the Gambia), $12 \%$ (Nairobi), and $15 \%$ (Johannesburg).

We have found that LGV is not a common cause of genital ulceration in the Gambia, which agrees with the figure of $1 \%$ in Johannesburg. Classically, it is said that extremely high titres of circulating antichlamydial antibody are found in this condition; ${ }^{18}$ it has been shown in Swaziland, however, that $C$ trachomatis may be isolated from genital ulcers of patients with low titres of circulating antibody detected by MIF. ${ }^{19}$ Whether these are true cases of LGV or represent urethral contamination of the ulcers is not known. We have isolated an LGV strain of $C$ trachomatis (L2) from a patient with ophthalmia neonatorum in the Gambia (Forsey T, Mabey D, unpublished observation), but failed to isolate chlamydiae from 46 genital ulcers from which uncontaminated specimens were obtained (Mabey D, unpublished observation). Of seven patients in the present study with chlamydial antibody titres of more than $1 / 250$, three also had serological evidence of syphilis. Of the other four patients, only one had a clinical diagnosis of LGV. On the other hand, we have isolated $H$ ducreyi from the buboes of three patients with a clinical diagnosis of LGV who did not have ulcers at presentation. We conclude, as have others, ${ }^{11}$ that the clinical diagnosis of gential ulcers in the tropics is unreliable.

It is not clear why herpes simplex virus should be isolated from such a small proportion of ulcers in Africa, when it is the commonest pathogen isolated in developed countries. ${ }^{78}$ The low isolation rate may be due to the relatively late presentation of genital ulcers in African clinics (table 1), but information on length of history has not been given in most studies. Alternatively, the high prevalence of serum antibody to herpes simplex virus types 1 and 2 in African communities may indicate a degree of immunity. It has been shown that neutralising antibodies to herpes simplex virus type 2 are often acquired in childhood in one African city. ${ }^{20}$

Méheus has proposed guidelines for the treatment of genital ulcers in African clinics without laboratory facilities. ${ }^{21}$ We have confirmed his view that cotrimoxazole two tablets twice daily for one week, combined with saline washes, is an effective regimen for the treatment of chancroid; this is reflected in our in vitro findings, all isolates of $H$ ducreyi being found to be sensitive to trimethoprim (Wall RA, unpublished observation). In view of the high proportion of genital ulcers that is due to chancroid, we have recommended that the optimum treatment for this condition in Gambian health centres should be cotrimoxazole and saline washes, as above, combined 
with a single intramuscular injection of benzathine penicillin 2.4 MIU.

We would like to thank Haddy Sillah for technical help.

\section{References}

1 Kibukamusoke JW. Venereal disease in East Africa. Trans $R$ Soc Trop Med Hyg 1965;59:642-8.

2 Piot P, Holmes KK. Sexually transmitted diseases. In: Warren KS, Mahmoud AAF, eds. Tropical and geographical medicine. New York: McGraw Hill, 1983.

3 Latif AS. Sexually transmitted diseases in clinic patients in Salisbury, Zimbabwe. British Journal Venereal Diseases 1981;57:181-3.

4 Méheus A, Van Dyck E, Friedman F. Genital infections in Swaziland. Ann Soc Belg Med Trop 1982;62:361-7.

5 Nsanze H, Fast MV, D'Costa LJ, Tukei P, Curran J, Ronald A. Genital ulcers in Kenya: clinical and laboratory study. British Journal of Venereal Diseases 1981;57:378-81.

6 Duncan MO, Bilgeri YR, Fehler HG, Ballard RC. The diagnosis of sexually acquired genital ulcerations in black patients in Johannesburg. Southern African Journal of Sexually Transmitted Diseases 1981;1:20-3.

7 Chapel T, Brown WJ, Jeffries C, Stewart JA. The microbiological flora of penile ulcerations. $J$ Infect Dis 1978;137:50-6.

8 Kinghorn GR, Hafiz S, McEntegart MG. Pathogenic microbial flora of genital ulcers in Sheffield with particular reference to herpes simplex virus and Haemophilus ducreyi. British Journal of Venereal Diseases 1982;58:377-80.

9 Méheus A, Van Dyck E, Ursi JP, Ballard RC, Piot P. Etiology of genital ulcerations in Swaziland. Sex Transm Dis 1983;10:33-5.

10 Chapel TA, Brown WJ, Jeffries C, Stewart JA. How reliable is the morphological diagnosis of penile ulceration? Sex Transm Dis 1977:4:150-2.
11 Fast MV, D'Costa LJ, Nsanze $\mathrm{H}$, et al. The clinical diagnosis of genital ulcer disease in men in the tropics. Sex Transm Dis 1984;11:72-6.

12 Joshi RM, Lawande RV. Chancroid in Nigeria. Trans $R$ Soc Trop Med Hyg 1983;77:665-7.

13 Sottnek FO, Biddle JW, Kraus SJ, Weaver RE, Stewart JA. Isolation and identification of Haemophilus ducreyi in a clinical study. J Clin Microbiol 1980;12:170-4.

14 Ripa KT, Mårdh P-A. New simplified culture techniques for Chlamydia trachomatis. In: Hobson D, Holmes KK, eds. Nongonococcal urethritis and related infections. Washington, DC: American Society for Microbiology 1977:323-7.

15 Treharne JD. Darougar S, Jones BR. Modification of the microimmunofluorescence test to provide a routine serodiagnostic test for chlamydial infection. J Clin Pathol 1977;30:510-7.

16 Forsey T, Darougar S. Indirect immunofluorescence test for detecting type-specific antibodies to herpes simplex virus. J Clin Pathol 1980;33:171-6.

17 Mabey DCW, Lloyd-Evans NE, Conteh S, Forsey T. Sexually transmitted diseases among randomly selected attenders at an antenatal clinic in The Gambia. British Journal Venereal Diseases 1984;60:331-6.

18 Schachter J, Dawson CR. Human chamydial infections. Littleton, Massachusetts: PSG Publishing Company, 1978.

19 Piot P, Ballard RC, Fehler HG, Van Dyck E, Ursi JP, Méheus AZ. Isolation of Chlamydia trachomatis from genital ulcerations in Southern Africa. In: Mårdh P-A. Holmes KK, Oriel JD, Piot P, Schachter J, eds. Chlamydial infections. Amsterdam: Elsevier Biomedical Press, 1982:115-8.

20 Sogbetun AO, Montefiore D, Anong CN. Herpes virus hominis antibodies among children and young adults in Ibadan. British Journal of Venereal Diseases 1976;55:44-7.

21 Méheus AZ. Practical approaches in developing nations. In: Holmes KK, Mårdh P-A, Sparling PF, Wiesner PJ, eds. Sexually transmitted diseases. New York: McGraw Hill, 1984: 998-1008. 